\title{
Combining reactive sputtering and rapid thermal processing for synthesis and discovery of metal oxynitrides
}

\author{
Lan Zhou, ${ }^{\text {b) }}$ Santosh K. Suram, ${ }^{\text {b) }}$ Natalie Becerra-Stasiewicz, Slobodan Mitrovic, Kevin Kan, \\ Ryan J.R. Jones, and John M. Gregoire ${ }^{\text {a) }}$ \\ Joint Center for Artificial Photosynthesis, California Institute of Technology, Pasadena, California 91125, USA
}

(Received 15 February 2015; accepted 28 April 2015)

\begin{abstract}
Recent efforts have demonstrated enhanced tailoring of material functionality with mixed anion materials, yet exploratory research with mixed anion chemistries is limited by the sensitivity of these materials to synthesis conditions. Synthesis of a particular metal oxynitride compound by traditional reactive annealing requires specific, limited ranges of both oxygen and nitrogen chemical potentials to establish equilibrium between the solid-state material and a reactive atmosphere. Using Ta-O-N as an example system, we describe a combination of reactive sputter deposition and rapid thermal processing (RTP) for synthesis of mixed anion inorganic materials. Heuristic optimization of reactive gas pressures to attain a desired anion stoichiometry is discussed, and the ability of RTP to enable amorphous to crystalline transitions without preferential anion loss is demonstrated through the controlled synthesis of nitride, oxide, and oxynitride phases.
\end{abstract}

\section{INTRODUCTION}

While metal oxides, nitrides, carbides, sulfides, etc. are widely used in numerous applications, such as electronics, optoelectronics, photocatalysis, and energy technologies, superior materials may be found in mixed anion inorganic materials, such as metal oxynitrides, ${ }^{1,2}$ oxychalcogenides, ${ }^{3-5}$ oxycarbides,${ }^{6}$ carbonitrides, ${ }^{7}$ borocarbides, ${ }^{8}$ and boronitrides. ${ }^{9}$ Due to their varied crystal structures, anion ordering, ${ }^{10}$ and ability to tune properties with anion composition, mixed anion inorganic materials span a broad range of physical, chemical, and electronic properties, providing opportunities to improve material performance for a variety of applications. ${ }^{11}$ In comparison to the extensive studies on mixed cation materials, ${ }^{12}$ relatively few synthesis methods and thus experimental evaluations of mixed anion materials exist.

Due to their tunable optical properties with N/O ratio, oxynitride materials are attractive candidates as visible-light-driven photoelectrocatalysts, spectral conversion phosphors, and transparent windows. ${ }^{1}$ In the field of solar fuels, the development of an efficient photoanode has remained a bottleneck due to the deep valence band energy (with respect to the standard equilibrium potential for water oxidation) of typically studied metal oxide semiconductors. $^{13}$ Metal nitride semiconductors generally

Contributing Editor: Rong-Jun Xie

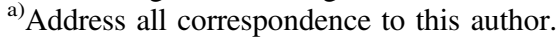

e-mail: gregoire@caltech.edu

${ }^{b}$ Equal contribution authors

DOI: $10.1557 / j \mathrm{mr} .2015 .140$ exhibit desirable band energetics for solar water oxidation with valence band energies more positive than metal oxide analogs, yet the chemical instability of metal nitrides in aqueous conditions has largely rendered them unsuitable for aqueous photoelectrocatalysis. Initial investigations into metal oxynitride compounds and oxide-nitride alloys have demonstrated the combined desirable properties of aqueous stability and band energetics necessary for a photoanode in a solar fuel device. ${ }^{14}$

To enable efficient exploration of metal oxynitride phase space, we describe a methodology for synthesis of oxynitride thin films using a combination of physical vapor deposition (PVD) and rapid thermal processing (RTP). We note that the technique may be expanded for the general synthesis of mixed anion materials. By regulating the partial pressure (PP) of $\mathrm{O}_{2}$ and $\mathrm{N}_{2}$ gases during reactive magnetron sputtering, anion stoichiometry can be systematically controlled and is unchanged during RTP crystallization of the film into high-temperature phases.

A variety of techniques, ${ }^{15}$ such as ammonolysis, ${ }^{1,16}$ chemical vapor deposition, ${ }^{17}$ intercalation, ${ }^{18}$ reactive cathodic arc evaporation, ${ }^{19}$ wet-chemical approaches, ${ }^{2}$ and $\mathrm{PVD}^{20,21}$ have been used for the synthesis of metal oxynitride materials. While ammonothermal treatments have been widely used for the synthesis of oxynitrides, ${ }^{1}$ high-temperature processing of oxides in $\mathrm{NH}_{3}$ to form oxynitrides requires careful control of reaction kinetics, as the formation of nitrides is thermodynamically favored over oxynitrides in the oxygen-free and high-nitrogen chemical potential environment. RTP of metal films in $\mathrm{O}_{2}$ and then in $\mathrm{NH}_{3}$ (Ref. 22) or directly in mixed $\mathrm{O}_{2} / \mathrm{N}_{2}$ 
(Ref. 23) has also been used to synthesize oxynitride thin films and requires careful calibration and control of annealing time-temperature-heating/cooling rate to obtain the desired composition and phase throughout the thickness of the film. While flux-assisted nitridation and ammonothermal synthesis have been used to achieve morphology and defect control in the synthesis of oxynitrides, ${ }^{2}$ precise tailoring of synthesis conditions for individual phases is necessary, limiting their application for exploration of new oxynitride phases.

The aim of our approach is to develop a versatile protocol that allows fine control of anion stoichiometry with independent heat treatment and is extendable to multi-cation synthesis. Reactive sputtering, using a mixture of reactive gases and a variety of sources (metals, metal oxides, metal nitrides, etc.), provides the ability to synthesize versatile mixed anion chemistries. ${ }^{24}$ Specifically, oxynitride compositions have been successfully deposited using mixed $\mathrm{O}_{2} / \mathrm{N}_{2}$ reactive sputtering. For $\mathrm{N}_{2}$ PPs sufficient to introduce significant nitrogen into the films, N/O stoichiometry varies nonlinearly as a function of the ratio of $\mathrm{N}_{2}$ and $\mathrm{O}_{2}$ gas flow rates, highlighting the importance of careful control and calibration of the reaction gas atmosphere. ${ }^{20,21,25-29}$ Using a variable leak valve to control $\mathrm{O}_{2}$ PP, we demonstrate the ability to carefully control $\mathrm{O}_{2}$ PPs and fine-tune oxynitride chemistries. We further discuss a heuristic approach to rapidly obtain the optimal $\mathrm{O}_{2}$ PP for depositing oxynitride films.

Typically, sputtered oxynitride thin films are either amorphous or contain a mixture of metal oxides and metal nitride phases..$^{20,21,23,25,27}$ While oxynitride phases have been observed in the as-deposited films in some cases, ${ }^{26,30,31}$ several factors such as total pressure, power, and substrate temperature during sputtering are likely to simultaneously control both the composition and crystal structure of the as-deposited oxynitride chemistries. To decouple the temperature-dependent reactivity of the growing film in sputter atmosphere and thermally activated crystallization, we demonstrate RTP as postdeposition, iso-compositional crystallization process that provides access to high-temperature phases without compromising anion stoichiometry. We discuss the variation of metal nitride, oxide, and oxynitride phase fractions as a function of reactive gas stoichiometry on a $\mathrm{Ta}-\mathrm{O}-\mathrm{N}$ system, a system of particular interest as a photocatalyst. $^{32}$

\section{EXPERIMENTAL}

The $\mathrm{TaO}_{x} \mathrm{~N}_{y}$ films were prepared in a custom-designed vacuum chamber (CMS 24, Kurt J. Lesker, Jefferson Hills, PA), as shown in Fig. 1, with base pressure of $6.7 \times 10^{-6}$ Pa maintained by a helium-cooled cryopump (CTI Cryo-Torr 8F). All the films were deposited at room temperature using $100 \mathrm{~W}$ direct current (DC) reactive

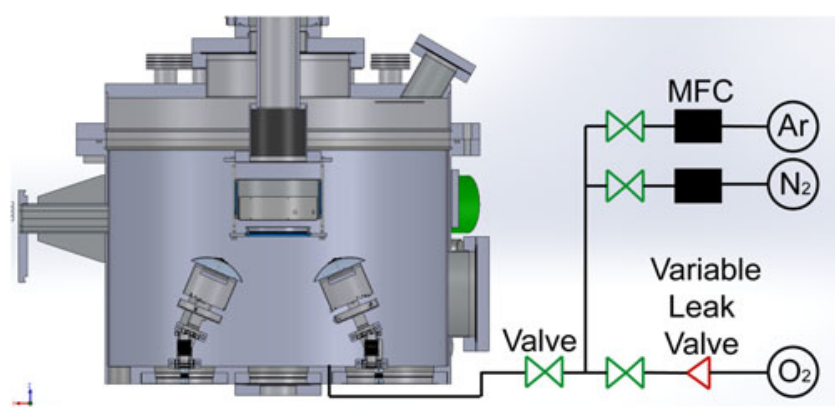

FIG. 1. Cross-section schematic of the custom-designed PVD chamber (Kurt J. Lesker CMS 24) and schematic of the gas flow manifold. The flow rates of $\mathrm{Ar}$ and $\mathrm{N}_{2}$ gases are controlled using MFCs, while $\mathrm{O}_{2}$ PP is controlled by adjusting the variable leak valve capable of pressure control at $10^{-4} \mathrm{~Pa}$ level.

magnetron sputtering of a metallic tantalum target (99.95\% purity from ACI Alloy, Inc.) in a mixed atmosphere of $\mathrm{Ar}, \mathrm{N}_{2}$, and $\mathrm{O}_{2}$ at a constant total working pressure of $0.8 \mathrm{~Pa}$. The flow rates of $\mathrm{Ar}$ and $\mathrm{N}_{2}$ gases were controlled using mass flow controllers (MFCs; MKS, 1179A Mass-Flo () with total pressure controlled by a capacitance manometer (MKS, 626B Baratron ${ }^{\circledR}$ ) feedback to a throttle valve on the cryopump. Control of $\mathrm{O}_{2}$ pressure was realized by adjusting a variable leak valve (Granville-Philips, series 203) providing $10^{-4} \mathrm{~Pa}$ precision, and the $\mathrm{O}_{2}$ pressure was measured by an ion gage prior to addition of other gases. The substrates used were $100 \mathrm{~mm}$ diameter $\mathrm{Si}$ (001) with a thermal oxide coating of approximately $170 \mathrm{~nm}$ (diffusion barrier) and were rotated at $5 \mathrm{rpm}$ during the deposition to ensure spatial uniformity of film composition and thickness. The Ta source was tilted at $20^{\circ}$ toward the chamber center, the vertical distance between target face and substrate was $65.5 \mathrm{~mm}$ and the horizontal distance between source center and substrate center was $165 \mathrm{~mm}$.

To calibrate and characterize the reactive sputtering rate, the mass deposition rate $\gamma\left(\mathrm{g} \mathrm{s}^{-1} \mathrm{~cm}^{-2}\right)$ was measured using a quartz crystal microbalance (QCM, Inficon SL-A configured with $6 \mathrm{MHz}$ Au-coated quartz crystals). The QCM sensor was placed in the same position as substrate center during thin film depositions. The measurement of mass deposition rate is independent of the film density, and measurements were made early in the QCM sensor lifetime to mitigate sensitivity to the film $Z$-factor, which was set to 1 for all measurements.

For each deposition, the Ta target was presputtered in argon (Ar) atmosphere at $0.8 \mathrm{~Pa}$ for $10 \mathrm{~min}$ to clean the target from possible target poisoning and contaminations. A series of $\mathrm{TaO}_{x} \mathrm{~N}_{y}$ thin films were deposited by varying $\mathrm{O}_{2}$ PP from 0 to $0.067 \mathrm{~Pa}$, while the $\mathrm{N}_{2}$ pressure was maintained at a relatively high $\mathrm{PP}$ of $0.2 \mathrm{~Pa}$ to ensure significant nitrogen incorporation. The as-deposited $\mathrm{TaO}_{x} \mathrm{~N}_{y}$ films were then annealed at approximately $1173 \mathrm{~K}$ for $30 \mathrm{~s}$ by RTP under flowing $\mathrm{N}_{2}$. To avoid 
anion exchange with surrounding atmosphere, an atmosphere better than $99.9 \%$ pure $\mathrm{N}_{2}$ was obtained by purging the $9 \mathrm{~L}$ RTP chamber at $13 \mathrm{lpm}$ for $240 \mathrm{~s}$. A lower $\mathrm{N}_{2}$ flow rate of $3 \mathrm{lpm}$ was used during RTP to avoid convective heat losses, followed by a flow rate of $13 \mathrm{lpm}$ during cool down. The active time of the RTP process is usually limited to few seconds, which limits significant in-film diffusion, and $\mathrm{N}_{2}$ gas maintains sufficient $\mathrm{N}_{2}$ vapor pressure to limit preferential nitrogen loss from the films.

The N/O ratios in the as-deposited and post-RTP films were measured using an Oxford Instruments X-Max $80 \mathrm{~mm}^{2}$ energy dispersive $\mathrm{x}$-ray spectroscopy (EDS; Oxford Instrument, Concord, MA) detector on a FEI Nova NanoSEM 450 (FEI, Hillsboro, OR) using $15 \mathrm{keV}$ electron beam. The crystal structure and phases of the films were determined by $\mathrm{x}$-ray diffraction (XRD) measurements using a Bruker DISCOVER D8 diffractometer (Bruker AXS, Inc., Madison, WI) with $\mathrm{Cu} \mathrm{K}_{\alpha}$ radiation. XRD images were collected using a two-dimensional VÅNTEC-500 detector (Bruker AXS, Inc., Madison, WI) and integrated into one-dimensional patterns using DIFFRAC.SUITE ${ }^{\mathrm{TM}}$ EVA software. For patterns in which multiple crystalline phases were identified, the relative phase fraction of each phase was approximated by normalizing the measured intensity of the most intense peak of each phase. While more quantitative models of phase concentrations can be applied, this straightforward calculation accurately captures the desired trends in phase concentration with respect to deposition conditions.

\section{RESULTS AND DISCUSSION}

In a reactive sputtering experiment, poisoning of the target surface may be characterized by the variation of mass deposition rate $(\gamma)$ as a function of reactive gas PP at fixed sputtering power. Mapping this relationship can provide insight into critical reactive gas pressures for anion incorporation into the sputtered films. For reactive sputtering from a Ta target, Fig. 2 shows variation of $\gamma$ as a function of $\mathrm{O}_{2} \mathrm{PP}$ with and without the presence of $\mathrm{N}_{2}$. Variation of $\gamma$ in the absence of $\mathrm{N}_{2}$ shows increase in $\gamma$ with increasing $\mathrm{O}_{2}$ PP until $0.013 \mathrm{~Pa}$, followed by continuous decrease of $\gamma$ and stabilization to a low $\gamma$ value beyond $0.27 \mathrm{~Pa}$. The initial increase may be in part due to the incorporation of oxygen interstitials in the growing metallic Ta film and is likely dominated by oxidation of the growing film at the substrate. ${ }^{33}$ In the range of $0.013-0.27 \mathrm{~Pa}$, the increase of $\mathrm{O}_{2} \mathrm{PP}$ results in a lower deposition rate, likely due to a corresponding increase in target poisoning by a surface oxide layer, which indicates the onset of significant target poisoning at $0.013 \mathrm{O}_{2}$ PP. Beyond $0.27 \mathrm{~Pa}$, a steady state metal oxide layer is likely formed on the target surface resulting in a relatively constant, low value of $\gamma$. For reactive

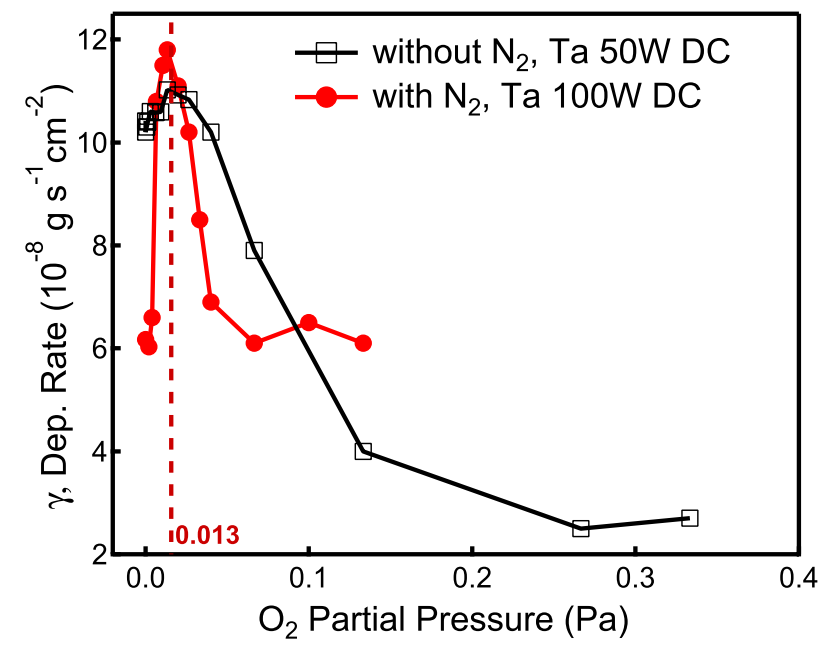

FIG. 2. Mass deposition rate $\gamma$ versus $\mathrm{O}_{2} \mathrm{PP}$ using 100 and $50 \mathrm{~W}$ DC power and $0.8 \mathrm{~Pa}$ total pressure with and without the presence of $\mathrm{N}_{2}(0.2 \mathrm{~Pa})$, respectively. The critical $\mathrm{O}_{2} \mathrm{PP}(0.013 \mathrm{~Pa})$ at which the maximal deposition rate is observed is marked.

sputtering in the presence of $\mathrm{N}_{2}$, the variation of $\gamma$ as a function of $\mathrm{O}_{2} \mathrm{PP}$ is observed to be qualitatively similar to its variation in the absence of $\mathrm{N}_{2}$, with the maximal deposition rate attained over a very fine range of $\mathrm{O}_{2} \mathrm{PP}$ near the critical value $(0.013 \mathrm{~Pa})$ for the onset of oxide target poisoning. Since Ta-O affinity is significantly higher than $\mathrm{Ta}-\mathrm{N}$ affinity, we suggest that optimal $\mathrm{O}_{2}$ $\mathrm{PP}$ for oxynitride synthesis is near the critical $\mathrm{O}_{2} \mathrm{PP}$ for the onset of target poisoning. The variation of deposition rate as a function of $\mathrm{O}_{2}$ and $\mathrm{N}_{2}$ PPs has been used to guide oxynitride film synthesis. ${ }^{21,26}$ However, deposition rate profiles in the presence of both $\mathrm{O}_{2}$ and $\mathrm{N}_{2}$ are not always easily interpreted due to several phenomena, such as competing metal-nitride and metal-oxide poisoning, varying sputtering rates of different metal-nitrides and corresponding variation in the sputter voltage. ${ }^{27}$ In such cases, a simple, heuristic identification of optimal $\mathrm{O}_{2} \mathrm{PP}$ for oxynitride synthesis is the $\mathrm{O}_{2} \mathrm{PP}$ at the onset of target poisoning, as observed from deposition rate profile in $\mathrm{Ar}-\mathrm{O}_{2}$ mixtures.

To illustrate the ability to tailor the N/O ratio in the deposited films, we present characterization of 10 independent thin films deposited at room temperature in the presence of $0.2 \mathrm{~Pa} \mathrm{~N}_{2}$ and with $\mathrm{O}_{2} \mathrm{PP}$ varying from 0.002 to $0.067 \mathrm{~Pa}$. Elemental analyses using energy dispersive spectroscopy (Fig. 3) before and after RTP confirm that the bulk-averaged N/O ratio in each film does not change significantly during the thermal processing. The thin film deposited at $0.013 \mathrm{~Pa} \mathrm{O}_{2} \mathrm{PP}$, corresponding to the onset of target poisoning, contains the N/O ratio close to 1 , verifying our heuristic for determination of optimal $\mathrm{O}_{2}$ PP for the synthesis of oxynitrides.

Figure 4(a) shows raw XRD patterns for the as-deposited $\mathrm{TaO}_{x} \mathrm{~N}_{y}$ films. Here, we present diffraction patterns without background subtraction to capture information regarding 


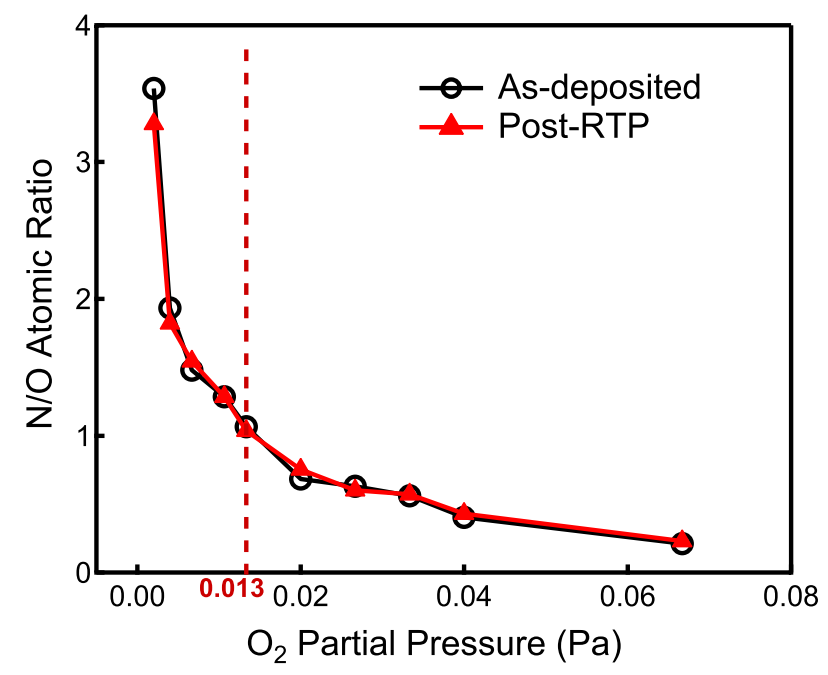

FIG. 3. N/O stoichiometry obtained from EDS measurements on both the as-deposited and post-RTP $\mathrm{TaO}_{x} \mathrm{~N}_{y}$ thin films as a function of $\mathrm{O}_{2}$ $\mathrm{PP}$ in the presence of $0.2 \mathrm{~Pa} \mathrm{~N}_{2}$.

signal to background ratio of the weakly crystalline as-deposited films. Only the pure nitride thin film shows significant crystallinity, predominantly corresponding to the $\mathrm{Ta}_{4} \mathrm{~N}_{5}$ phase. The XRD pattern for thin film deposited at $0.002 \mathrm{O}_{2}$ PP shows a broad peak centered at $\theta=33.4^{\circ}$, possibly due to short range order representative of the $\mathrm{Ta}_{3} \mathrm{~N}_{5}$ and $\mathrm{Ta}_{4} \mathrm{~N}_{5}$ phases. The XRD pattern of the thin film deposited at $0.013 \mathrm{O}_{2} \mathrm{PP}$, for which the N/O ratio is close to 1 , does not show any crystallographic features. Similar observations have been noted in the literature for poorly crystalline or amorphous oxynitride thin films. ${ }^{20,21,23,25,27}$ The XRD pattern for thin films deposited at $0.040 \mathrm{O}_{2} \mathrm{PP}$ shows the presence of a broad amorphous peak centered around the expected value for the $(1,11,0)$ peak of $\mathrm{Ta}_{2} \mathrm{O}_{5}$. A similar observation of low crystallinity for refractory oxide phases was observed during reactive sputter deposition of tungsten ${ }^{20}$ and titanium oxynitrides. ${ }^{27}$ The observation of poorly crystalline or amorphous thin films for the N/O stoichiometries of interest is in agreement with previous reports, and as described by Cristea et al., ${ }^{23}$ sputter deposited $\mathrm{TaO}_{x} \mathrm{~N}_{y}$ with $\mathrm{p}_{\mathrm{O}_{2}}+\mathrm{p}_{\mathrm{N}_{2}}>0.15 \mathrm{~Pa}$ encourages the formation of amorphous phases, which highlights the need for an independent thermal processing step to achieve amorphous to crystalline transitions in oxynitride systems.

Figure 4(b) shows XRD patterns of the corresponding four $\mathrm{TaO}_{x} \mathrm{~N}_{y}$ thin films after RTP, revealing systematic changes in the thin film structure with increasing $\mathrm{O}_{2} \mathrm{PP}$. The full set of $11 \mathrm{TaO}_{x} \mathrm{~N}_{y}$ thin film XRD patterns is shown in Fig. S1. The film deposited under the gas mixture of $\mathrm{Ar}$ and $\mathrm{N}_{2}$ without $\mathrm{O}_{2}$ shows the presence of the $\mathrm{Ta}_{4} \mathrm{~N}_{5}$ phase (tetragonal, PDF 01-075-0627). With introduction of $\mathrm{O}_{2}$ at $\mathrm{PP}$ as low as $0.002 \mathrm{~Pa}$, an oxynitride $\beta$-TaON (monoclinic, PDF 01-071-0178) appears and the $\mathrm{Ta}_{4} \mathrm{~N}_{5}$ phase is partially transformed to the $\mathrm{Ta}_{3} \mathrm{~N}_{5}$ (monoclinic, PDF 03-065-1247) structure. The appearance of
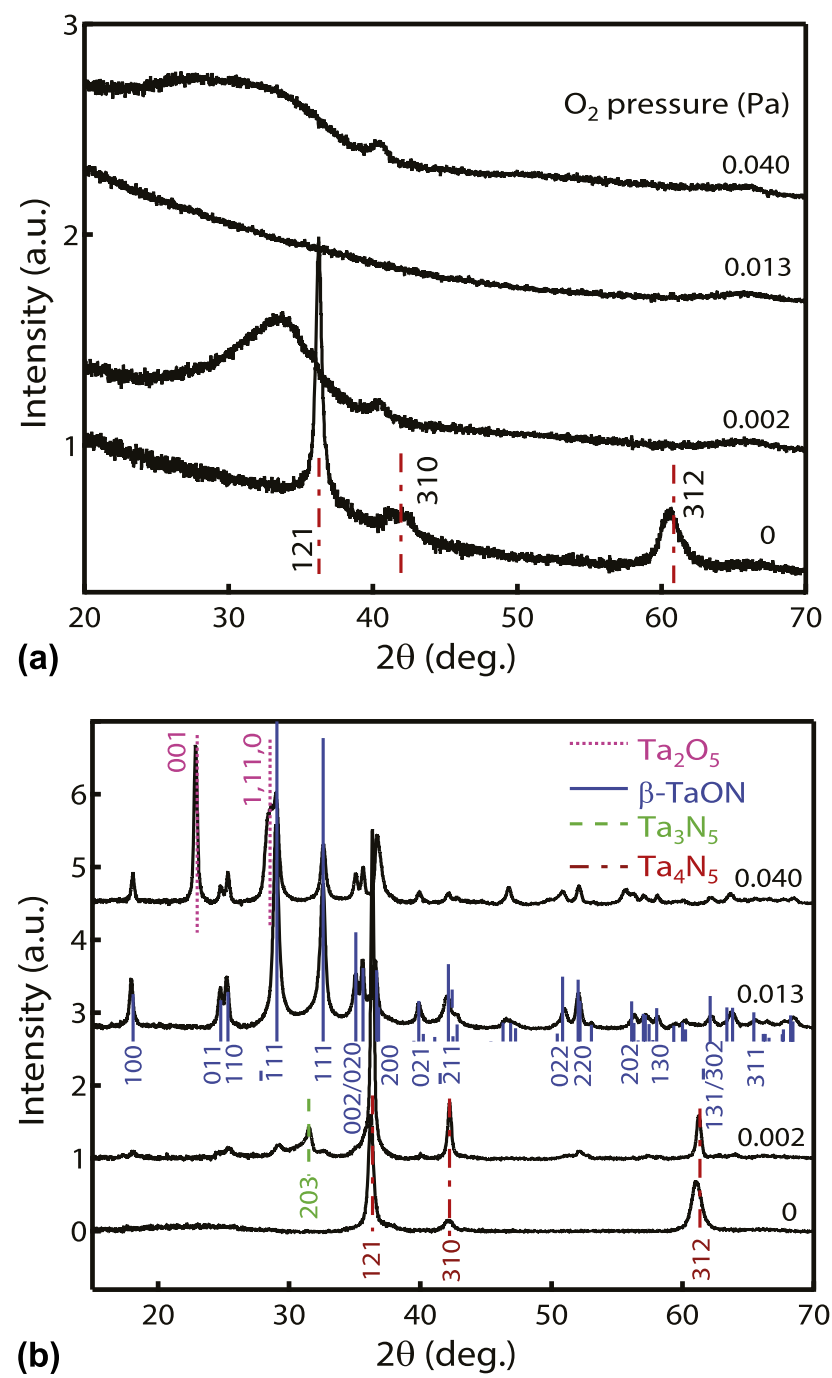

FIG. 4. XRD patterns of the $\mathrm{TaO}_{x} \mathrm{~N}_{y}$ samples as a function of $\mathrm{O}_{2} \mathrm{PP}$ with $0.2 \mathrm{~Pa} \mathrm{~N}_{2} \mathrm{PP}$. (a) XRD patterns of the as-deposited samples where only the sample with $\mathrm{O}_{2}$ PP of 0 exhibits a crystalline phase. (b) XRD patterns for the samples after being annealed with RTP at approximately $1173 \mathrm{~K}$ for $30 \mathrm{~s}$ under $\mathrm{N}_{2}$ flow. The patterns of XRD peaks for four phases are noted.

higher oxidation state nitride $\left(\mathrm{Ta}_{3} \mathrm{~N}_{5}\right)$ in the presence of low- $\mathrm{O}_{2}$ PP may be due to O-incorporation in the film, and for the purpose of tracking the evolution of oxynitride phases with respect to nitride and oxide structures, Fig. 5 shows the combined fractions of nitride phases along with the fractions of oxide and oxynitride phases for each $\mathrm{O}_{2}$ PP. The molar fraction of tantalum nitride phases $\left(\mathrm{Ta}_{3} \mathrm{~N}_{5}\right.$ and $\left.\mathrm{Ta}_{4} \mathrm{~N}_{5}\right)$ decreases with increasing $\mathrm{O}_{2} \mathrm{PP}$ and almost disappears at critical $\mathrm{O}_{2} \mathrm{PP}$ of $0.013 \mathrm{~Pa}$, where $\beta$-TaON is the primary phase. As shown in Fig. 2, this value of $\mathrm{O}_{2}$ PP corresponds to the maximum mass deposition rate both in the presence and absence of $\mathrm{N}_{2}$. On increasing $\mathrm{O}_{2}$ PP above this critical PP, tantalum nitride phases are no longer observed, and $\mathrm{Ta}_{2} \mathrm{O}_{5}$ (orthorhombic, PDF 00-025-0922) appears and grows at 


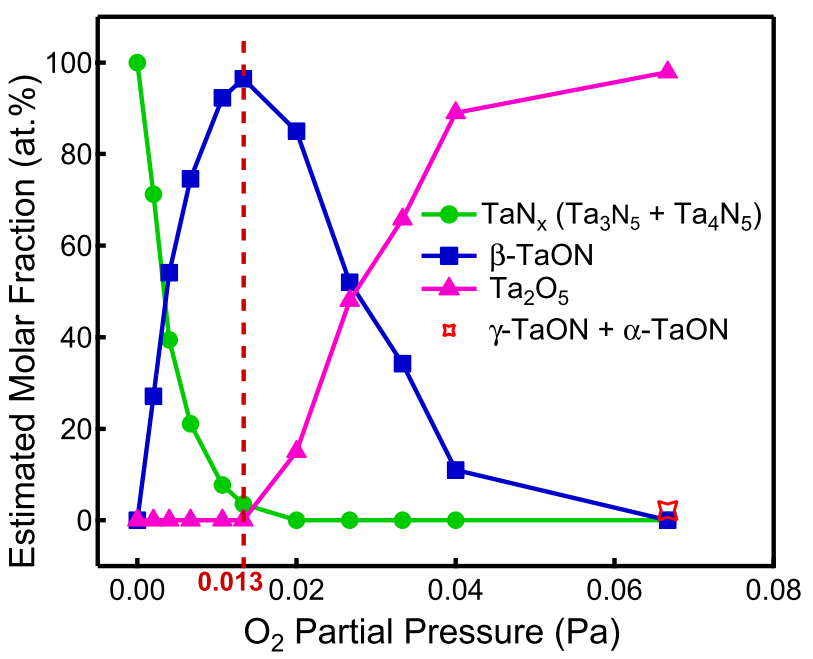

FIG. 5. The estimated molar fraction of the different phases formed at each $\mathrm{TaO}_{x} \mathrm{~N}_{y}$ thin film deposited at various $\mathrm{O}_{2}$ PPs and fixed $\mathrm{N}_{2} \mathrm{PP}$ of $0.2 \mathrm{~Pa}$. The critical $\mathrm{O}_{2} \mathrm{PP}$ corresponding to maximum deposition rate is marked and corresponds to the maximum molar fraction of the $\beta$-TaON phase.

the expense of the $\beta-\mathrm{TaON}$ phase. This is consistent with the onset of oxide target poisoning at $\mathrm{O}_{2} \mathrm{PP}$ of $0.013 \mathrm{~Pa}$. An interesting note is that at the highest $\mathrm{O}_{2} \mathrm{PP}$ of $0.067 \mathrm{~Pa}$, additional minor XRD peaks are observed and can be explained by the introduction of two minority TaON phases, $\gamma$-TaON (monoclinic, PDF 01-076-3258) and $\alpha$-TaON (hexagonal, PDF 01-072-2067), which are polytypes of the $\beta-\mathrm{TaON}$ phase obtained at lower $\mathrm{O}_{2} \mathrm{PP}$ (see Fig. S1 in Supplementary Document). The as-deposited film contains sufficient nitrogen to form these minority phases (see Fig. 3), and further investigation will be required to determine whether these phases grow within the $\mathrm{Ta}_{2} \mathrm{O}_{5}$ matrix or on the film surface during RTP.

In total, the evolution of nitride, oxynitride, and oxide phases with $\mathrm{O}_{2} \mathrm{PP}$ between 0 and $0.067 \mathrm{~Pa}$ is quite similar to that of a pseudo-binary phase diagram with end-member nitride and oxide phases that exhibit low solubility of $\mathrm{N}$ onto $\mathrm{O}$ sites and vice-versa. The primary ternary compound, $\beta-\mathrm{TaON}$, appears as a line compound at $\mathrm{O}_{2} \mathrm{PP}$ of $0.013 \mathrm{~Pa}$, as the N/O stoichiometry varies nonlinearly with $\mathrm{O}_{2} \mathrm{PP}$. The phase distributions suggest that the total anion concentration with respect to $\mathrm{Ta}$, i.e., $(\mathrm{O}+\mathrm{N}) / \mathrm{Ta}$, increases from 1.25 to 2 to 2.5 as the dominant phase evolves from $\mathrm{Ta}_{4} \mathrm{~N}_{5}$ to $\beta-\mathrm{TaON}$ to $\mathrm{Ta}_{2} \mathrm{O}_{5}$. The EDS measurements are not sensitive to anion point defects in these structures, and under the assumption that the compounds are nearly stoichiometric, the as-deposited anion concentration in the poorly crystalline films is approximately equal to that of the targeted line compounds. These results indicate that the optimized reactive sputtering introduces the appropriate anion concentration such that subsequent crystallization into line compounds can occur without additional anion incorporation. The QCM-based heuristic identification of the near-optimal deposition atmosphere of a metal oxynitride can be readily applied for other metal sputter targets. The independent variation of the RTP temperature can be used to optimize oxynitride film quality for a given application or to form specific high-temperature phases.

\section{CONCLUSIONS}

We demonstrate the synthesis of oxynitride films with varying $\mathrm{N} / \mathrm{O}$ composition via reactive magnetron sputtering of $\mathrm{Ta}$ in the presence of $\mathrm{N}_{2}$ and very low- $\mathrm{O}_{2} \mathrm{PP}$. The tunability of the N/O composition is achieved by controlling the $\mathrm{O}_{2}$ PP between 0 and $0.067 \mathrm{~Pa}$ using a variable leak valve with a fixed $\mathrm{N}_{2} \mathrm{PP}$ of $0.2 \mathrm{~Pa}$ and Ar-balanced total pressure of $0.8 \mathrm{~Pa}$. For deposition from a given metal target, the mass deposition rate as a function of $\mathrm{O}_{2}$ PP can be measured in situ. The $\mathrm{O}_{2} \mathrm{PP}$ that maximizes the deposition rate can be readily determined and serves as a heuristic measure of the near-optimal $\mathrm{O}_{2}$ PP for synthesizing oxynitride phases, as this $\mathrm{O}_{2} \mathrm{PP}$ corresponds to the onset of substantial oxide poisoning of the target. Crystallization of nitride, oxide, and oxynitride phases without anion exchange is demonstrated using RTP. This method is applicable to mixing anions using other reactive gases $\left(\mathrm{NH}_{3}\right.$, $\mathrm{CH}_{4}, \mathrm{H}_{2} \mathrm{~S}$, etc.) and can be extended for multi-cation depositions as well, providing a new platform for efficient synthesis and exploration of multi-anion thin films.

\section{ACKNOWLEDGMENTS}

This study is based upon work performed by the Joint Center for Artificial Photosynthesis, a DOE Energy Innovation Hub, supported through the Office of Science of the U.S. Department of Energy (Award No. DESC0004993). The authors thank the Kurt J. Lesker company for assistance with the design of the custom PVD gas handling system.

\section{REFERENCES}

1. R-J. Xie and H.T. Bert Hintzen: Optical properties of (oxy)nitride materials: A review. J. Am. Ceram. Soc. 96, 665 (2013).

2. Y. Moriya, T. Takata, and K. Domen: Recent progress in the development of (oxy)nitride photocatalysts for water splitting under visible-light irradiation. Coord. Chem. Rev. 257, 1957 (2013).

3. A. Ishikawa, T. Takata, J.N. Kondo, M. Hara, H. Kobayashi, and K. Domen: Oxysulfide $\mathrm{Sm}_{2} \mathrm{Ti}_{2} \mathrm{~S}_{2} \mathrm{O}_{5}$ as a stable photocatalyst for water oxidation and reduction under visible light irradiation $(\lambda \leq 650 \mathrm{~nm})$. J. Am. Chem. Soc. 134, 13547 (2002).

4. K. Ueda, S. Inoue, S. Hirose, H. Kawazoe, and H. Hosono: Transparent p-type semiconductor: LaCuOS layered oxysulfide. Appl. Phys. Lett. 77, 2701 (2000).

5. Y-L. Pei, J. He, J-F. Li, F. Li, Q. Liu, W. Pan, C. Barreteau, D. Berardan, N. Dragoe, and L-D. Zhao: High thermoelectric performance of oxyselenides: Intrinsically low thermal conductivity of Ca-doped. BiCuSeO. NPG Asia Mater. 5, e47 (2013).

6. W-C.J. Wei and M-H. Lo: Processing and properties of (Mo,Cr) oxycarbides from MOCVD. Appl. Organomet. Chem. 12, 201 (1998). 
7. S-h. Jhi, J. Ihm, and S.G. Louie: Electronic mechanism of hardness enhancement in transition-metal carbonitrides. Nature 399, 1 (1999).

8. K-H. Müller and V.N. Narozhnyi: Interaction of superconductivity and magnetism in borocarbide superconductors. Rep. Prog. Phys. 64, 943 (2001).

9. N. Imamura, H. Mizoguchi, and H. Hosono: Superconductivity in $\mathrm{LaT}(\mathrm{M}) \mathrm{BN}$ and La3T(M2)B2N3 (T(M) = transition metal) synthesized under high pressure. J. Am. Chem. Soc. 134(5), 2516 (2012).

10. M. Yang, J. Oró-Solé, J.A. Rodgers, A.B. Jorge, A. Fuertes, and J.P. Attfield: Anion order in perovskite oxynitrides. Nat. Chem. 3, 47 (2011).

11. J.A. Schottenfeld, A.J. Benesi, P.W. Stephens, G. Chen, P.C. Eklund, and T.E. Mallouk: Structural analysis and characterization of layer perovskite oxynitrides made from Dion-Jacobson oxide precursors. J. Solid State Chem. 178, 2313 (2005).

12. M.L. Green, I. Takeuchi, and J.R. Hattrick-Simpers: Applications of high throughput (combinatorial) methodologies to electronic, magnetic, optical, and energy-related materials. J. Appl. Phys. 113, 231101 (2013).

13. M.G. Walter, E.L. Warren, J.R. McKone, S.W. Boettcher, Q. Mi, E.A. Santori, and N.S. Lewis: Solar water splitting cells. Chem. Rev. 110, 6446 (2010).

14. Y.B. Wu, P. Lazic, G. Hautier, K. Persson, and G. Ceder: First principles high throughput screening of oxynitrides for watersplitting photocatalysts. Energy Environ. Sci. 6(1), 157 (2013).

15. S.G. Ebbinghaus, H-P. Abicht, R. Dronskowski, T. Müller, A. Reller, and A. Weidenkaff: Perovskite-related oxynitridesRecent developments in synthesis, characterisation and investigations of physical properties. Prog. Solid State Chem. 37, 173 (2009).

16. S. Pokrant, A.E. Maegli, G.L. Chiarello, and A. Weidenkaff: Perovskite-related oxynitrides in photocatalysis. Chimia 67, 162 (2013).

17. J. Dupuis, E. Fourmond, D. Ballutaud, N. Bererd, and M. Lemiti: Optical and structural properties of silicon oxynitride deposited by plasma enhanced chemical vapor deposition. Thin Solid Films 519, 1325 (2010).

18. Y-I. Kim, Y. Paik, and M. Avdeev: Intercalation route to complex perovskites $\mathrm{AM}_{0.2} \mathrm{Ta}_{0.8} \mathrm{O}_{2.8} \mathrm{~N}_{0.2}(\mathrm{~A}=\mathrm{Sr}, \mathrm{Ba} ; \mathrm{M}=\mathrm{Li}, \mathrm{Na})$ : Neutron diffraction and nuclear magnetic resonance study. Cryst. Growth Des. 15, 53-61 (2014).

19. M. Laurikaitis, J. Dudonis, and D. Milčius: Deposition of zirconium oxynitride films by reactive cathodic arc evaporation and investigation of physical properties. Thin Solid Films 516, 1549 (2008).

20. S.H. Mohamed and A. Anders: Structural, optical, and electrical properties of $\mathrm{WO}_{\mathrm{x}}\left(\mathrm{N}_{\mathrm{y}}\right)$ films deposited by reactive dual magnetron sputtering. Surf. Coat. Technol. 201, 2977 (2006).
21. S.H. Mohamed, A.M. Abd El-Rahman, and M.R. Ahmed: Investigation of zirconium oxynitride thin films deposited by reactive pulsed magnetron sputtering. J. Phys. D: Appl. Phys. 40, 7057 (2007).

22. V.A. Matylitskaya, W. Bock, K. Thoma, and B.O. Kolbesen: Formation of niobium oxynitrides by rapid thermal processing (RTP). Appl. Surf. Sci. 252, 205 (2005).

23. D. Cristea, A. Crisan, N.P. Barradas, E. Alves, C. Moura, F. Vaz, and L. Cunha: Development of tantalum oxynitride thin films produced by PVD: Study of structural stability. Appl. Surf. Sci. 285, 19 (2013).

24. J. Ford, A. Welch, C. Caskey, B. Van Zeghbroeck, P. Parilla, D. Ginley, A. Zakutayev, and J. Perkins: Sulfide and oxide-sulfide combinatorial libraries by co-sputtering with an atomic sulfur source. Bull. Am. Phys. Soc. 59(1), (2014).

25. S. Venkataraj, O. Kappertz, R. Jayavel, and M. Wuttig: Growth and characterization of zirconium oxynitride films prepared by reactive direct current magnetron sputtering. J. Appl. Phys. 92, 2461 (2002).

26. S. Venkataraj, H. Kittur, R. Drese, and M. Wuttig: Multitechnique characterization of tantalum oxynitride films prepared by reactive direct current magnetron sputtering. Thin Solid Films 514, 1 (2006).

27. S.H. Mohamed, O. Kappertz, J.M. Ngaruiya, T. Niemeier, R. Drese, R. Detemple, M.M. Wakkad, and M. Wuttig: Influence of nitrogen content on properties of direct current sputtered $\mathrm{TiO}_{\mathrm{x}} \mathrm{N}_{\mathrm{y}}$ films. Phys. Status Solidi A 201, 90 (2004).

28. C.K. Chung, T.S. Chen, and N.W. Chang: Effect of reactive gases flow ratios on the microstructure and electrical resistivity of $\mathrm{Ta}-\mathrm{N}-\mathrm{O}$ thin films by reactive co-sputtering. Thin Solid Films 519, 5099 (2011).

29. J-M. Chappé, N. Martin, J. Lintymer, F. Sthal, G. Terwagne, and J. Takadoum: Titanium oxynitride thin films sputter deposited by the reactive gas pulsing process. Appl. Surf. Sci. 253, 5312 (2007).

30. S.K. Rawal, A.K. Chawla, R. Jayaganthan, and R. Chandra: Effect of power variation on wettability and optical properties of co-sputtered titanium and zirconium oxynitride films. Bull. Mater. Sci. 36, 403 (2013).

31. J. Tao, J.W. Chai, L.M. Wong, Z. Zhang, J.S. Pan, and S.J. Wang: Growth of single crystalline $\mathrm{TaON}$ on yttria-stabilized zirconia (YSZ). J. Solid State Chem. 204, 27 (2013).

32. G. Hitoki, T. Takata, J.N. Kondo, M. Hara, H. Kobayashi, and K. Domen: An oxynitride, $\mathrm{TaON}$, as an efficient water oxidation photocatalyst under visible light irradiation (lambda $<$ or $=500$ nm). Chem. Commun. 2, 1698 (2002).

33. E. Hollands and D.S. Campbell: The mechanism of reactive sputtering. J. Mater. Sci. 3, 544 (1968).

\section{Supplementary Material}

To view supplementary material for this article, please visit http://dx.doi.org/jmr.2015.140. 